\title{
Dynamics of erosion and deposition in tokamaks
}

\author{
A. Kreter ${ }^{a^{*}}$, S. Brezinsek ${ }^{\mathrm{a}}$, J.P. Coad ${ }^{\mathrm{b}}$, H.G. Esser ${ }^{\mathrm{a}}$, W. Fundamenski ${ }^{\mathrm{b}}$, V. Philipps ${ }^{\mathrm{a}}$, \\ R.A. Pitts ${ }^{\mathrm{c}}$, V. Rohde ${ }^{\mathrm{d}}$, T. Tanabe ${ }^{\mathrm{e}}$, A. Widdowson ${ }^{\mathrm{b}}$ and JET EFDA contributors ${ }^{* *}$ \\ JET-EFDA, Culham Science Centre, OX14 3DB, Abingdon, UK \\ ${ }^{a}$ Institut für Energieforschung - Plasmaphysik, Forschungszentrum Jülich, \\ Association EURATOM-FZJ, Trilateral Euregio Cluster, Germany \\ ${ }^{b}$ EURATOM-UKAEA Fusion Association, Culham Science Centre, Abingdon, UK \\ ${ }^{c}$ CRPP, Association EURATOM-EPFL, Lausanne, CH-1015, Switzerland \\ ${ }^{d}$ Max-Planck-Institut für Plasmaphysik, EURATOM Association, Garching, Germany \\ ${ }^{e}$ Interdisciplinary Graduate School of Engineering Science, Kyushu University, Hakozaki 6-10-1, \\ Higashi-ku, Fukuoka 812-8581, Japan
}

\begin{abstract}
In recent years, a general qualitative understanding has been reached about the major pathways of material migration in divertor tokamaks. Main chamber wall components have been identified as the major source of material erosion. The eroded material is transported by scrape-off layer flows, in the case of the ion $\boldsymbol{B} \times \nabla \boldsymbol{B}$ drift pointing towards the X-point, predominately towards the inner divertor leg, where it is deposited in the form of amorphous layers. On JET, where carbon is the main plasma-facing material, it has been found that the presence of deposited carbon rich layers determines the dynamic characteristics of further redistribution of carbon, in particular towards remote areas. The transport from the strike point to the deposition location is mainly line-of-sight. The amount of eroded carbon depends on the surface type, with lower rates for the bare CFC and higher rates for deposited layers. The erosion rates in the inner divertor increase non-linearly with increasing ELM energies.
\end{abstract}

JNM keywords: Carbon, Divertor Materials, First Wall Materials, Plasma-Materials 
Interaction, Redeposition, Surface Effects, Thermal Shock

PSI-17 keywords: Amorphous Films, Carbon-based materials, Disruption, Divertor, Dust,

ELM, Erosion \& Deposition, Hydrocarbons, Impurity transport, JET, Power deposition, Sputtering

PACS: 28.52.Fa, 52.40.Hf, 52.55.Fa

* Corresponding author address: Forschungszentrum Jülich, IEF-4, 52425 Jülich, Germany.

*Corresponding author E-mail: A.Kreter@fz-juelich.de

Presenting author: Arkadi Kreter

** See the Appendix of M.L. Watkins, et al., Fusion Energy 2006 (Proc. 21st Int. Conf.

Chengdu) [International Atomic Energy Agency (IAEA), Vienna, 2006].

\section{Introduction}

There will be diverse criteria to evaluate the success of the ITER project [1]. The first objective will be the capability of the device to produce a certain amount of fusion power $(\sim 500 \mathrm{MW})$ for a certain discharge duration $(\sim 400 \mathrm{~s})$. The second, and no less important objective will be the availability of the reactor during its envisaged operation period. Although recipes are available to fulfil each of these individual requirements, the major challenge of the ITER project will be to satisfy the combination of these criteria.

The availability of ITER will strongly depend on the performance of PFCs. In the first instance, erosion will limit the lifetime of PFCs. The eroded material can be transported over long distances and be re-deposited as amorphous layers ([1] and references therein). Codeposition of tritium in such layers could become the main limiting factor for reactor availability due to safety restrictions [1]. Of special concern are co-deposited layers growing in remote locations, areas shadowed from direct contact with plasma. These remote locations are hard for currently available cleaning techniques to access [2] and can offer a reservoir for 
tritium accumulation. Gaps of castellated PFCs are a special type of remote areas specific for ITER [3]. The crucial role of shadowed areas is illustrated by the deuterium-tritium experiment DTE1 in JET in 1997, after which the vast majority of retained tritium was found in the form of hydrogen rich carbon layers on the cooled louvre structures in the pumping duct of the inner divertor leg $[4,5]$. In the case of metallic plasma-facing materials, the amount of material transported to remote areas can be significantly reduced [6].

To achieve the required fusion gain of $Q \sim 10$, the envisaged baseline scenario for ITER is operation in ELMy H-mode with a stored energy of $W \sim 350 \mathrm{MJ}$ [1]. High quality H-modes are usually associated with type I ELMs, which can release a substantial fraction $\Delta W_{E L M}$ of stored energy to the wall ( $\Delta W_{E L M} / W$ of up to $\left.\sim 10 \%\right)$. Such repetitive events will likely cause unacceptable high erosion of the plasma-facing components (PFCs) [7,8], thus negatively affecting the availability of ITER. Investigations of specific carbon and tungsten materials proposed for ITER PFCs have resulted in ELM loads being further restricted to $0.5 \mathrm{MJ} / \mathrm{m}^{2}$ [9], corresponding to $\Delta W_{E L M} \sim 1 \mathrm{MJ}$ in ITER.

Results of post-mortem observations and refined experimental techniques, such as ${ }^{13} \mathrm{CH}_{4}$ tracer injection, in ASDEX Upgrade [10,11,12], DIII-D [13,14], JET [4,5,15,16] and JT-60U $[17,18]$ have led to a general understanding about the major pathways of material in divertor tokamaks. Protruding elements of the main chamber wall have been identified as the main source of material erosion in machines with carbon PFCs. Both net-erosion and netdeposition are often observed in different areas of the outer divertor, giving integrally a more balanced picture with respect to the deposition dominated inner divertor. Some of material eroded in the outer divertor can escape there and be redistributed in the vessel. Scrape-off layer (SOL) flows [5] largely define the fate of eroded material. In the case of "normal" magnetic field direction with the ion $\boldsymbol{B} \times \nabla \boldsymbol{B}$ drift pointing towards the X-point, the SOL flow drives the material predominately towards the inner divertor leg, where it is deposited in the 
form of amorphous layers. Although the underlying physics of the asymmetric SOL flows is not yet understood, their existence in JET has been proved by Mach probe measurements [19], where the reversal of the field direction dramatically affected the in-out asymmetry of the flow direction. Consequently, with reversed B-field a layer growth in the outer divertor was observed [20].

The recent progress in understanding the mechanisms of material erosion, migration and deposition in tokamaks is largely based on the development of novel in-situ erosiondeposition diagnostics. In contrast to traditional post-mortem analysis, which delivers a campaign averaged footprint of material erosion and deposition, these techniques are focused on the identification and the quantification of processes determining the carbon migration by time resolved measurements. Quartz microbalance (QMB) deposition monitors are one of such in-situ diagnostics. QMB systems have been successfully employed in JET [21], ASDEX Upgrade [10], NSTX [22] and other tokamaks. During the MkII-HD divertor operation in JET in 2005-2007, QMB systems were installed in the inner and outer louvre areas and below tile 5 (also known as load bearing septum replacement plate, LBSRP), facing the inner divertor (Fig. 1). A distinctive feature of the inner and outer QMBs are their remotely controlled shutter systems. This feature allows the operator to choose a "region-ofinterest" time window in a particular plasma discharge, e.g. phases with certain magnetic field configurations, auxiliary heating and other discharge actuators. The lower sensitivity limit of the QMB systems in JET in terms of areal densities of carbon atoms is $\approx 1 \cdot 10^{15} \mathrm{C} / \mathrm{cm}^{2}$, corresponding to about one monolayer of co-deposited film. Due to the remote position of the QMB only particles escaping the plasma with line-of-sight trajectories, i.e. neutral particles and dust, can be detected. The QMB measures the net-effect: deposition of incoming carbon, less erosion by the impinging neutral deuterium flux. Note that due to the QMB viewing geometry higher deposition on the QMB reflects higher carbon erosion from the target plate. 
The aim of this work is to summarize the experimental efforts to investigate dynamic features of material transport in tokamaks. In particular, this includes effects of erosion and deposition in the divertor as function of the magnetic field configuration in both static and varying (sweep) regimes, plasma confinement mode and transients in heat and particle loads.

JET is the tokamak in existence with discharge parameters most relevant to reactor conditions [23]. Moreover, JET is uniquely equipped with diagnostics for the study of dynamic aspects of erosion and deposition [24]. Therefore, the results presented here are based largely on those obtained during the recent experimental campaigns in JET. In particular, a broad QMB database has been evolved during the recent JET campaigns, which allows for systematic studies of correlations between the erosion and deposition behaviour in the divertor and various discharge conditions.

The influence of surface layers on carbon migration including ELM-induced enhanced erosion is described in section 2. Section 3 deals with static effects of geometry on transport, while section 4 describes the aspects of geometry variations. The influence of disruptions on deposition in remote areas is shown in section 5. In section 6, the results are summarised and the implications for ITER are discussed.

\section{Surface layers and ELM-induced enhanced erosion}

An increase of erosion of the target in the inner divertor of JET during H-mode operation with respect to the L-mode has been reported [25]. A systematic study and comparison of the deposition data in the inner and outer divertor louvres have become possible after an upgrade of the QMB system. Fig. 2 shows deposition rates on the inner and outer QMBs as functions of ELM energy drop. For this subset of data, only pulses with a symmetric magnetic field configuration with both strike points (SP) at the horizontal target tiles have been considered, as indicated in Fig. 1. In this geometry line-of-sight from the SP positions to the respective QMBs is achived. There is a sharp contrast between the results for 
the inner and outer divertor. For the latter, there is no obvious dependence on ELM size, whilst at the inner louvre deposition rates increase significantly with ELM energy. For $\Delta W_{E L M}>100 \mathrm{~kJ}$ the dependence of deposition rates at the inner QMB on ELM energy becomes less pronounced, largely due to the compensating effect of the lower frequencies associated with larger type I ELMs [26].

In JET, the amount of energy transported by ELMs to the inner divertor leg is characteristically a factor of $\sim 2$ higher with respect to energy going to the outer divertor [27]. However, with the range of ELM energies of up to $430 \mathrm{~kJ}$, as shown in Fig. 2, the amount of ELM energy towards the outer target should be sufficient to trigger the ELM-induced enhanced erosion in this region, but this was not observed. Therefore, the marked in-out asymmetry of deposition cannot be exclusively attributed to the difference in ELM energy fractions transported to the inner and outer divertor legs. The in-out asymmetry can however be explained by the presence of permanent carbon layers with a typical thickness of several tens of $\mu \mathrm{m}$ deposited all over the inner target. Post-mortem surface analysis of divertor target tiles after the MkII-HD campaign has shown a significantly lower amount of deposition at the position of the outer strike point at tile 6 chosen for the study of the ELM influence. Moreover, the deposition in the outer leg has different composition with a significant fraction of beryllium, implying different structural properties with respect to layers in the inner divertor [28]. Higher atom and molecule carbon light emission [29] and radiative energy losses [30] in the inner divertor are also evidence for the asymmetry observed in the deposition between the inner and outer divertor legs. Laboratory investigations have furthermore demonstrated that hydrogenated carbon layers are more sensitive to thermal loads than bare graphite due to different structural properties [31].

Using the deposition rates measured by the inner QMB for discharges with ELMs of several hundreds kJ, simple geometric estimations result in carbon erosion rates from the 
inner target of few $10^{17}$ atoms $/ \mathrm{cm}^{2} \mathrm{~s}$, or several tens of $\mathrm{nm} / \mathrm{s}$ in terms of layer thickness. Though little is known about the time-resolved carbon deposition rates in the vicinity of the $\mathrm{SP}$ in the inner divertor, it is save to assume that the high ELM-induced erosion prevails the inter-ELM deposition there. It is conceivable that in discharges series with large ELMs and stable position of the inner SP no layer growth in this area would occur.

From the data in Fig. 2, deposition on the inner QMB can be attributed to single ELMs as function of their size (Fig. 3). The details of the iterative procedure used to separate the contributions of different ELMs by means of a self-consistent fit function are given in [32]. The fit function is the sum of two terms. The first, with a linear dependence on ELM size, represents physical sputtering by impinging deuterium calculated for a yield of $1.5 \%$. For ELM energies of a few $100 \mathrm{~kJ}$, sputtering fails to reproduce experimental observations by at least one order of magnitude. Instead, this non-linear behaviour can be well described by the second term, $\sim \exp \left(W_{a} / \Delta W_{E L M}\right)$, with fit coefficient $W_{a}=680 \mathrm{~kJ}$ as an effective activation energy of the process. The Arrhenius-like behaviour suggests a thermal nature for this ELMinduced enhanced erosion of carbon layers.

The underlying mechanism for thermal decomposition of carbon layers is still under discussion. The process can be attributed to the release of a large family of hydrocarbons from co-deposited layers [29,31]. Though the mean free path of hydrocarbon molecules under ELM conditions is $<1 \mathrm{~mm}$, their large number, aided by the step-by-step erosion - re-deposition process, can lead to some particles escaping ELMs towards the inner louvre area.

Alternatively, thermal release of particle clusters (dust) can explain the transport of carbon over a distance of $\sim 10 \mathrm{~cm}$ from the target to the louvre without strong attenuation even for harsh ELM conditions [33]. At estimated equilibrium temperatures of dust particles in the divertor plasma from $2000 \mathrm{~K}$ to $4000 \mathrm{~K}$ [33], their hydrogen and beryllium content would probably be released before arriving in the inner louvre. Dust particles of sub-micrometer size 
can gain velocities up to $\sim 1000 \mathrm{~m} / \mathrm{s}$ and be destroyed upon collision with the wall [34]. The background flux of neutral deuterium can then lead to the saturation of the carbon layer with deuterium corresponding to the layer temperature, in agreement with the hydrogen-rich characteristic of the carbon layers observed on the cooled structure of the inner louvre [4].

Radiation-enhanced sublimation (RES) [35] is less likely to be the cause of the ELMinduced enhanced erosion, as, firstly, for high particle fluxes during large ELMs the yield of RES-induced erosion would be less than the yield of physical sputtering, and, secondly, RES should act similarly in the outer divertor, which was not observed.

\section{Influence of magnetic field and divertor geometry on erosion}

Post-mortem analysis of deposition patterns in JET suggested that the carbon transport towards the inner louvre is mainly line-of-sight [4]. Previously reported QMB measurements in the inner louvre show a clear dependence of deposition rates on the position of the inner SP, with highest values when the SP is positioned at the horizontal target with line-of-sight to the QMB position [25]. Measurements by the inner QMB during JET campaign 2005-2007 confirm these findings (Fig. 4). A similar observation was made in ASDEX Upgrade. Here, a variation of the outer SP position changes the deposition rates on the QMBs facing the outer divertor with highest rates when line-of-sight between the SP position and QMB is established [10]. This was attributed to erosion and transport of high-sticking hydrocarbon radicals.

The QMB placed below tile 5 and facing the inner divertor of JET, see Fig. 1, shows a distinctive behaviour with respect to the inner SP position. It is in a pronounced net-erosion regime when the inner SP is placed at the horizontal tile 4 but deposition dominated when the SP moves to the vertical tile 3 [36]. Note that in the case of the inner SP placed on tile 4, the predominant behaviour of the QMBs in the inner louvre (net-deposition) and under tile 5 (neterosion) is different. This can be explained by different viewing geometries of both QMBs, 
with the inner one observing only tile 4 and its vicinity and the QMB under tile 5 having the large part of the inner divertor in its view. The different viewing geometries change the balance at the QMBs between deposition of carbon coming mostly from the SP position and erosion by deuterium atoms originating from the entire observation volume.

The inner dome region in JT-60U is in the PFR facing the inner divertor leg, analogous to the position of the QMB under tile 5 in JET. Campaign integrated, this region in JT-60U is erosion dominated [17]. However, under certain conditions net-deposition can be achieved at the inner dome, for example in the ${ }^{13} \mathrm{CH}_{4}$ puffing experiment where methane was injected into the outer divertor and subsequently detected at the inner dome region [18]. This behaviour may be attributed to dynamic features of erosion and deposition, though not necessarily to the SP position only.

No clear correlation has been observed between the deposition on the QMB at the outer louvre and the outer SP position (Fig. 5a). This is in sharp contrast to the behaviour in the inner divertor with dominating line-of-sight transport, underlining the different mechanisms of carbon erosion in the inner and outer divertor legs with different surface conditions. A correlation was however observed between deposition on the outer QMB and the position of the inner SP (Fig. 5b). Despite strong scatter of data, the mean value is negative, indicating net-erosion, when the inner SP is at horizontal tile 4 which is largely shadowed from the outer divertor leg by tile 5. Shifting the inner SP upwards along the vertical target increases deposition in the outer louvre. This tendency is more pronounced in discharges with large ELMs, when more carbon is released from the inner target (cf. section 2). This observation suggests that the inner target is one of the main sources of carbon to the outer divertor. The additional source of carbon can significantly change the balance between gross erosion and gross deposition in the outer divertor, thus changing the net-behaviour of the outer QMB from erosion to deposition dominated. If the release of dust particles is the cause of the ELM- 
induced enhanced erosion of the inner target, it is conceivable that these clusters can be transported line-of-sight towards the outer divertor even through the outer SOL [30].

The observed dynamic behaviour can explain the development of deposition in the outer louvre for different divertor configurations in the history of JET. During the MkIIA divertor operation, which includes DTE1, the vast majority of the applied configurations were with both SPs at the respective horizontal targets, suggesting a low carbon flux from the inner to the outer divertor leg. No significant deposition was detected in the outer divertor [4]. For MkII-GB, the programme comprised a considerable fraction of configurations with the SPs at the vertical targets. However, the septum, separating the inner and outer divertor legs and hindering particles to cross the PFR, may be the reason there was no significant deposition in the outer louvre [15]. It was the MkII-SRP divertor, for which for the first time a substantial amount of deposition was observed in the outer louvre [16]. The deposition in this region accumulated over the campaign corresponded to $\sim 1 / 3$ of the deposition in the inner louvre. The septum replacement plate could allow eroded particles to travel across the PFR, thus changing the balance in the outer divertor in favour of deposition. A similar integral behaviour with reduced asymmetry between the inner and outer louvre areas has been observed for the MkII-HD campaign.

\section{Erosion induced by variations of strike point positions}

It has been observed in JET, that a shift of the inner SP to a position, which was not subjected to significant heat loads in previous discharges, induces strong additional erosion. The corresponding deposition rates measured by the inner QMB are up to $\sim 4$ times higher than in cases when the corresponding target positions were conditioned in previous discharges [25,37]. The so-called "shot history effect" is attributed to enhanced erosion of layers deposited in previous discharges. The spectroscopic observations show significant higher intensities of hydrocarbon products when such freshly deposited layers are eroded, indicating 
a different, hydrogen rich structure of these layers. Typically, after $\sim 10 \mathrm{~s}$ of $\mathrm{H}$-mode operation with type I ELMs the erosion rates decay to a stationary value corresponding to erosion of the permanent layers in the inner divertor.

Fig. 6 illustrates the shot history effect in a dedicated series of similar discharges [37]. Since several discharges before this series were conducted with the inner SP at the vertical target (not shown here), the first pulse with the SP at the horizontal target caused strong deposition on the QMB, which dropped significantly in the second pulse. In pulses 3-5 the SP was shifted to the vertical target. The layer accumulated on the horizontal target during these three pulses caused increased deposition in pulse 6 . In pulse 7, the deposition rate returned to a stationery value for a conditioned target.

In NSTX, similarly, an increase of deposition in remote areas has been observed after a change in plasma shape that exposes a previous deposition area to erosion [22].

Periodic variations (sweeps) of the SP positions are one of the potential solutions to increase the lifetime of the targets in ITER [38]. The QMB data in JET show, however, that SP sweeps cause a multiple increase of the deposition rates, accompanied by fuel retention, in the remote area (the inner louvre). A possible explanation is a permanent "refreshment" of carbon layers by sweeps and consequently increased erosion of the layers.

\section{Erosion induced by disruptions}

Uncontrolled disruptions are a potential threat for the ITER PFCs, as unacceptably high particle and heat fluxes can hit the wall and cause damage to it [39]. In contrast, mitigated disruptions [40] would lead to tolerable wall loads and can even have a positive affect on the release of trapped fuel from the wall [41]. Therefore, mitigated disruptions are discussed as a routine discharge termination procedure in ITER [2].

In the 2005-2007 campaign in JET, six disruptions occurred during exposure of the inner QMB and three during the outer (Table 1). To ascertain the fraction of deposition 
caused by the disruption, a similar non-disruptive pulse has been taken as reference. For all analysed discharges the disruptions caused a strong additional deposition in both inner and outer remote areas. The amount of deposition does not correlate with the force on the vessel, a measure for vessel vibrations caused by the disruption. However, the amount of energy released during the quench phase appears to be crucial (Fig. 7).

It is conceivable that the mechanism causing enhanced erosion during disruptions is of the same nature as the mechanism of ELM-induced erosion, namely thermal decomposition of co-deposited layers. In contrast to the normal operation, the magnetic field configurations

prior to disruptions do not appear to influence deposition. This suggests a significant broadening of the heat load patters during disruptions, in agreement with previous observations [39].

\section{Summary and discussion}

Even though the major pathways of the material transport in modern tokamaks have been identified, the dynamic aspects of material migration remain an issue of ongoing research. On JET it has been found, based on QMB measurements, that the presence of thick hydrogenated deposited layers in the inner divertor determines the characteristics of further re-distribution of carbon, in particular towards remote areas shadowed from the direct plasma impact. These mechanisms can explain the amounts and the in-out asymmetries of codeposited carbon and hydrogenic isotopes typically found in areas of the JET divertor inaccessible to the plasma.

The transport in the divertor is mainly line-of-sight, i.e. by neutral or dust particles, which predominately originate from the inner strike point position and travel over distances of up to several centimetres across the magnetic field to the inner louvre area and the PFR. The carbon flux from the inner target appears to change significantly the erosion-deposition balance in the outer divertor leg. 
The amount of eroded carbon depends on the surface type, with lower rates for the bare CFC and higher rates for deposited layers. The highest rates are obtained after a shift of the strike point position to the "fresh", hydrogen-rich layers deposited in previous discharges ("shot history effect"). SP sweeps cause a strong increase of deposition and fuel retention in remote areas and, therefore, are not recommended as method to improve the target lifetime or for the target conditioning in a reactor with carbon wall.

There is a clear non-linear increase of the erosion rates in the inner divertor of JET with increasing ELM energies. This ELM-induced enhanced erosion is attributed to the thermal decomposition of carbon layers in the inner divertor by release of hydrocarbons and/or by increased production of carbon particle clusters (dust). The erosion enhancement is most pronounced for ELMs with $\Delta W_{E L M}>\sim 100 \mathrm{~kJ}$. This value is well above ELM energy ranges of all present-day tokamaks with exception of JET. Therefore this effect is unlikely to be observable in tokamaks in existence other than JET. If carbon is used for PFCs in ITER, however, even ELMs below the revised design limit of $\sim 0.5 \mathrm{MJ} / \mathrm{m}^{2}$ can cause a similar increase of erosion. Since only the re-deposited carbon layers appear to be affected by ELMs, the effect probably would not substantially increase the total amount of eroded carbon in the machine but the distribution of re-deposition. In particular, it would lead to enhanced carbon migration towards shadowed areas hardly accessible by cleaning techniques.

Unmitigated disruptions in JET cause significant additional deposition in the remote areas. Assuming every discharge in JET is terminated by a mid-sized disruption, a multiple increase of the total amount of deposition in the louvre areas can be expected. The ongoing experimental programme of JET should provide an answer whether mitigated disruptions are an option for reducing the fuel retention in a tokamak reactor.

\section{Acknowledgments}

This work, supported by the European Communities under the contract of Association 
between EURATOM/FZJ, was carried out within the framework of the European Fusion Development Agreement. The views and opinions expressed herein do not necessarily reflect those of the European Commission.

\section{References}

[1] Progress in the ITER Physics Basis, Nucl. Fusion 47 (2007).

[2] G. Counsell, P. Coad, C. Grisola, et al., Plasma Phys. Control. Fusion 48 (2006) B189.

[3] K. Krieger, W. Jacob, D.L. Rudakov, et al., J. Nucl. Mater. 363-365 (2007) 870.

[4] J.P. Coad, P.L. Andrew and A.T. Peacock, Phys. Scr. T81 (1999) 7.

[5] J.P. Coad, N. Bekris, J.D. Elder, et al., J. Nucl. Mater. 290-293 (2001) 224.

[6] M.J. Rubel, J.P. Coad and R.A. Pitts, J. Nucl. Mater. 367-370 (2007) 1432.

[7] G. Federici, A. Loarte and G. Strohmayer, Plasma Phys. Control. Fusion 45 (2003) 1523.

[8] A. Loarte, G. Saibene, R. Sartori, et al., Plasma Phys. Control. Fusion 45 (2003) 1549.

[9] A. Zhitlukhin, N. Klimov, I. Landman, et al., J. Nucl. Mater. 363-365 (2007) 301.

[10] V. Rohde, R. Dux, M. Mayer, et al., Phys. Scr. T111 (2004) 49.

[11] M. Mayer, V. Rohde, J. Likonen, et al., J. Nucl. Mater. 337-339 (2005) 119.

[12] E. Vainonen-Ahlgren, J. Likonen, T. Renvall, et al., J. Nucl. Mater. 363-365 (2007) 270.

[13] S.L. Allen, W.R. Wampler, A.G. McLean, et al., J. Nucl. Mater. 337-339 (2005) 30.

[14] W.R. Wampler, A.G. McLean, S.L. Allen, et al., J. Nucl. Mater. 363-365 (2007) 72.

[15] J.P. Coad, J. Likonen, M. Rubel, et al, Nucl. Fusion 46 (2006) 350.

[16] J.P. Coad, P. Andrew, S.K. Erents, et al., J. Nucl. Mater. 363-365 (2007) 287.

[17] Y. Gotoh, T. Tanabe, Y. Ishimoto, et al., J. Nucl. Mater. 357 (2006) 138.

[18] Y. Nobuta, K. Masaki, T. Arai, et al., in: 34th EPS Conference on Plasma Phys. Warsaw, 2-6 July 2007 ECA Vol.31F, P-1.024.

[19] R.A. Pitts, P. Andrew, X. Bonnin, et al., J. Nucl. Mater. 337-339 (2005) 146.

[20] P. Andrew, J.P. Coad, Y. Corre, et al., J. Nucl. Mater. 337-339 (2005) 99. 
[21] H.G. Esser, G. Neill, P. Coad, et al., Fusion Eng. Des. 66-68 (2003) 855.

[22] C.H. Skinner, H.W. Kugel, A.L. Roquemore, et al., J. Nucl. Mater. 363-365 (2007) 247.

[23] M.L. Watkins, et al., Fusion Energy 2006 (Proc. 21st Int. Conf.Chengdu) [International Atomic Energy Agency (IAEA), Vienna, 2006].

[24] J.P. Coad, H.G. Esser, J. Likonen, et al., Fusion Eng. Des. 74 (2005) 745.

[25] H.G. Esser, V. Philipps, M. Freisinger, et al., J. Nucl. Mater. 337-339 (2005) 84.

[26] A. Loarte, G. Saibene, R. Sartori, et al., Phys. Plasmas 11 (2004) 2668.

[27] T. Eich, A. Kallenbach, R.A. Pitts, et al., J. Nucl. Mater. 363-365 (2007) 989.

[28] J.P. Coad, private communication.

[29] S. Brezinsek, A. Pospieszczyk, M.F. Stamp, et al., J. Nucl. Mater. 337-339 (2005) 1058.

[30] A. Huber, R.A. Pitts, A. Loarte, et al., J. Nucl. Mater. 390-391 (2009) 830.

[31] K. Maruyama, W. Jacob and J. Roth, J. Nucl. Mater. 264 (1999) 56.

[32] A. Kreter, H.G. Esser, S. Brezinsek, et al., Phys. Rev. Lett. 102 (2009) 045007.

[33] S.I. Krasheninnikov, Y. Tomita, R. D. Smirnov and R. K. Janev, Phys. Plasmas 11 (2004) 3141.

[34] R.D. Smirnov, S.I. Krasheninnikov, A.Yu. Pigarov, et al., J. Nucl. Mater., doi:10.1016/j.jnucmat.2009.01.090.

[35] W. Eckstein and V. Philipps, in Physical Processes of the Interaction of Fusion Plasmas with Solids, edited by W. Hofer and J. Roth (Academic Press, San Diego, 1996), p. 93.

[36] H.G. Esser, A. Kreter, V. Philipps, et al., J. Nucl. Mater. 390-391 (2009) 148.

[37] S. Brezinsek, M.F. Stamp, A. Kreter, et al., in: 34th EPS Conference on Plasma Phys. Warsaw, 2-6 July 2007 ECA Vol.31F, P-1.050.

[38] S. Droste, D. Borodin, A. Kirschner, et al., Contrib. Plasma Phys. 46 (2006) 628.

[39] A. Loarte, G. Saibene, R. Sartori, et al., Phys. Scr. T128 (2007) 222.

[40] D.G. Whyte, T.C. Jernigan, D.A. Humphreys, et al., Phys. Rev. Lett. 89 (2002) 055001. 
[41] V. Philipps, M. Freisinger, A. Huber, T. Loarer, J. Nucl. Mater. 390-391 (2009) 478. 
Table 1. Disruptive pulses considered by the QMB investigations in JET.

\begin{tabular}{|c|c|c|c|c|c|c|c|c|c|}
\hline $\begin{array}{l}\text { Disruptive } \\
\text { pulse }\end{array}$ & $\begin{array}{l}\text { Reference } \\
\text { non- } \\
\text { disruptive } \\
\text { pulse }\end{array}$ & $\begin{array}{l}\mathrm{W}_{\mathrm{dia}} \\
{[\mathrm{MJ}]}\end{array}$ & $\begin{array}{l}\text { Force } \\
\text { on } \\
\text { vessel } \\
{[\mathrm{MN}]}\end{array}$ & $\begin{array}{l}\text { Position } \\
\text { inner SP } \\
\text { before } \\
\text { disruption }\end{array}$ & $\begin{array}{l}\text { Position } \\
\text { outer SP } \\
\text { before } \\
\text { disruption }\end{array}$ & $\begin{array}{l}\text { Deposition } \\
\text { on inner } \\
\text { QMB in } \\
\text { disruptive } \\
\text { pulse } \\
{\left[\mathrm{C} / \mathrm{cm}^{2}\right]}\end{array}$ & $\begin{array}{l}\text { Deposition } \\
\text { on inner } \\
\text { QMB in } \\
\text { reference } \\
\text { pulse } \\
{\left[\mathrm{C} / \mathrm{cm}^{2}\right]}\end{array}$ & $\begin{array}{l}\text { Deposition } \\
\text { on outer } \\
\text { QMB in } \\
\text { disruptive } \\
\text { pulse } \\
{\left[\mathrm{C} / \mathrm{cm}^{2}\right]}\end{array}$ & $\begin{array}{l}\text { Deposition } \\
\text { on outer } \\
\text { QMB in } \\
\text { reference } \\
\text { pulse } \\
{\left[\mathrm{C} / \mathrm{cm}^{2}\right]}\end{array}$ \\
\hline 64814 & 64813 & 0.4 & 0.55 & tile 4 & tile 6 & $2.9 \cdot 10^{15}$ & $1.5 \cdot 10^{14}$ & $\mathrm{n} / \mathrm{a}$ & $\mathrm{n} / \mathrm{a}$ \\
\hline 65073 & 65072 & 1.0 & 1.46 & tile 3 & tile 6 & $5.1 \cdot 10^{15}$ & $4.3 \cdot 10^{14}$ & $\mathrm{n} / \mathrm{a}$ & $\mathrm{n} / \mathrm{a}$ \\
\hline 65138 & 65137 & 1.3 & 1.15 & tile 3 & tile 6 & $2.8 \cdot 10^{15}$ & $8.5 \cdot 10^{14}$ & $7.2 \cdot 10^{14}$ & $-2.0 \cdot 10^{14}$ \\
\hline 66191 & 66189 & 0.5 & 0.83 & tile 4 & tile 7 & $3.0 \cdot 10^{15}$ & $3.2 \cdot 10^{14}$ & $1.4 \cdot 10^{15}$ & $7.3 \cdot 10^{14}$ \\
\hline 66299 & 66298 & 3.2 & 0.93 & tile 1 & tile 5 & $1.1 \cdot 10^{16}$ & 0 & $2.4 \cdot 10^{16}$ & $5.1 \cdot 10^{14}$ \\
\hline 68496 & 68495 & 4.4 & 2.52 & tile 3 & tile 6 & $2.4 \cdot 10^{16}$ & $2.3 \cdot 10^{12}$ & $\mathrm{n} / \mathrm{a}$ & $\mathrm{n} / \mathrm{a}$ \\
\hline
\end{tabular}




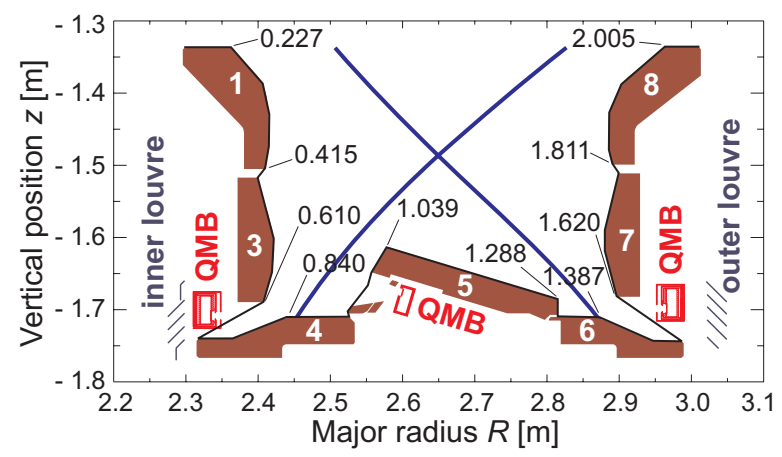

Fig. 1. Poloidal cross-section of the MkII-HD divertor deployed during the JET campaign of 2005-2007 with numbers as used in the text to denote the CFC divertor target tiles. The scoordinate is measured along the contour of the tiles. Values of the s-coordinate in meters at some critical points are given. The separatrix of the magnetic field configuration common to the pulses of the QMB database used in Fig. 2 and Fig. 3 is shown. 


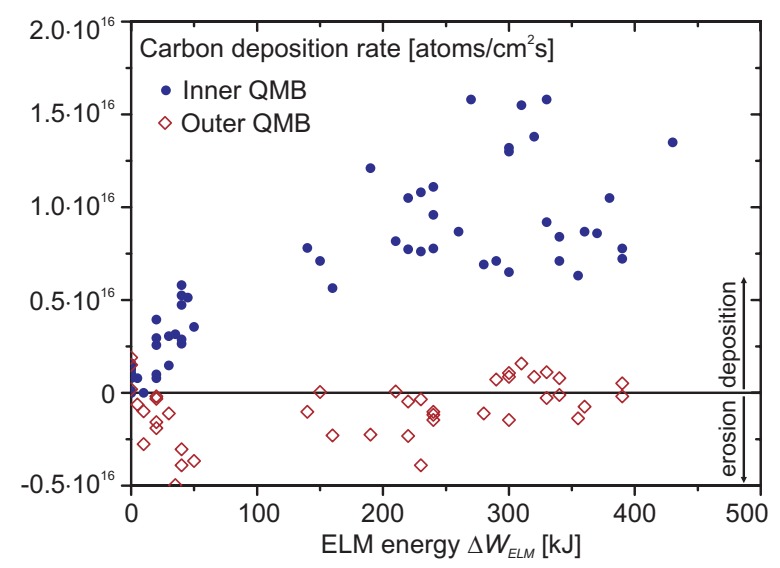

Fig. 2. Carbon deposition rates in the inner $(\bullet)$ and outer $(\diamond)$ louvres of JET as function of ELM stored energy drop. 


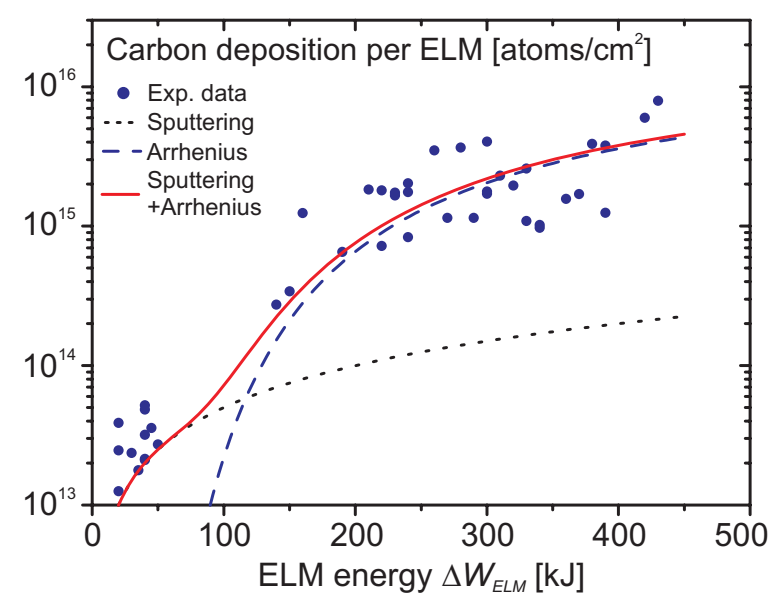

Fig. 3. Amount of carbon deposited on the inner louvre in JET per single ELM as function of ELM stored energy drop. (•) QMB data; (-) Fit function comprising $(\cdots)$ ) linear term for physical sputtering and (- - ) Arrhenius term for thermal decomposition. 


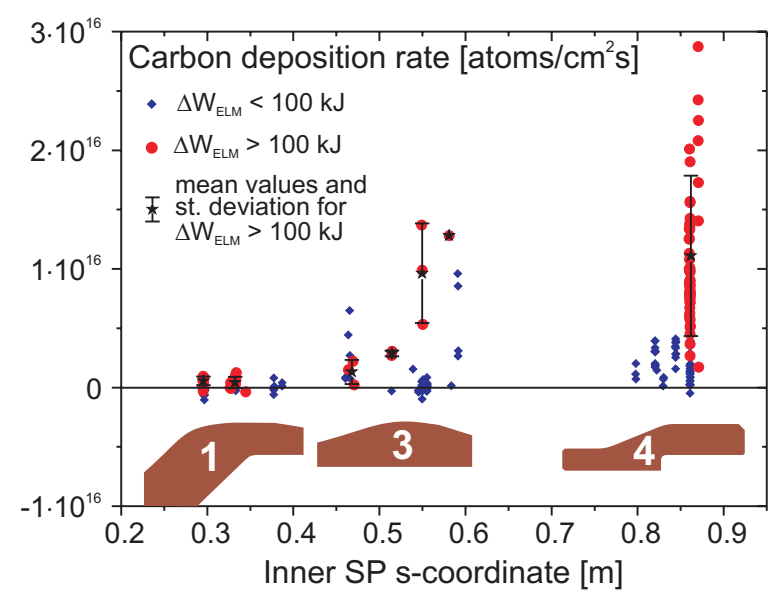

Fig. 4. Carbon deposition rate on the inner louvre QMB of JET as function of the inner SP position. Mean values are calculated for groups of data points with $\Delta \mathrm{W}_{\mathrm{ELM}}>100 \mathrm{~kJ}$ corresponding to certain SP positions. Images of tiles indicate the SP positions (cf. Fig. 1). 

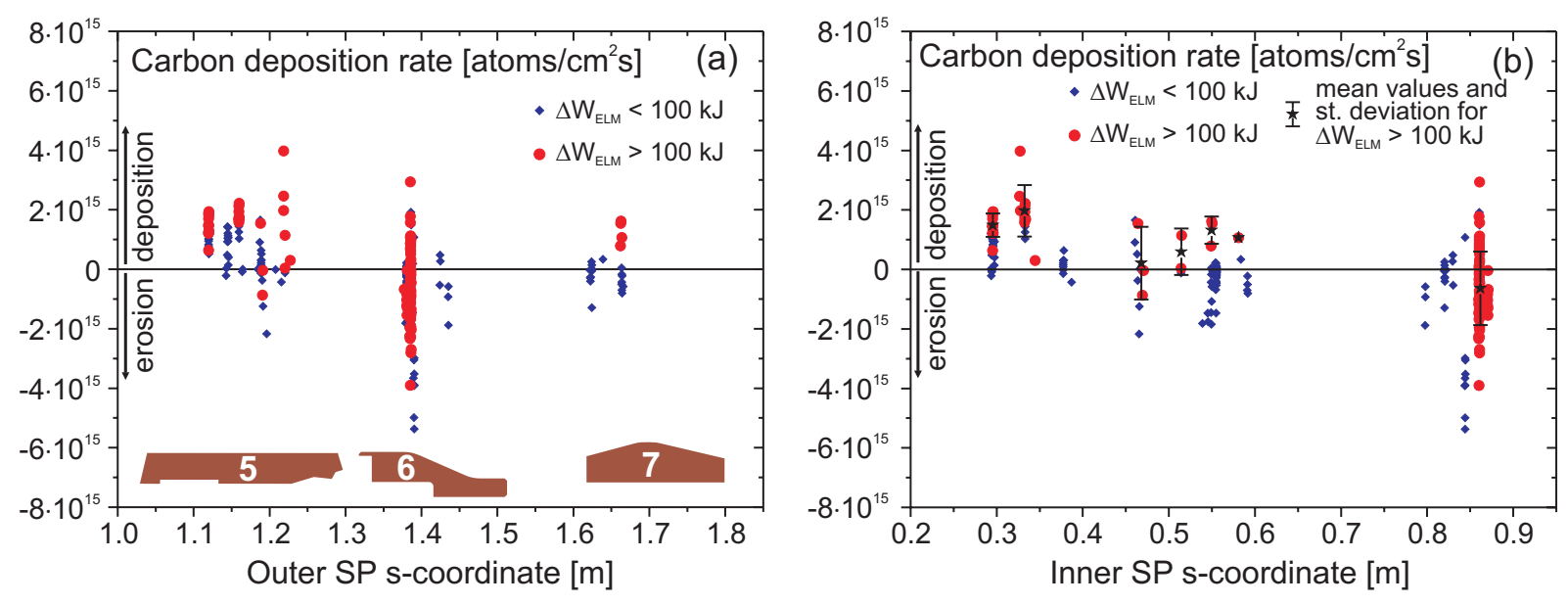

Fig. 5. Carbon deposition rate on the outer louvre QMB of JET as function of (a) the outer SP position and (b) the inner SP position. In (b), mean values are calculated for groups of data points with $\Delta \mathrm{W}_{\mathrm{ELM}}>100 \mathrm{~kJ}$ corresponding to certain SP positions. Images of tiles indicate the SP positions (cf. Fig. 1). 


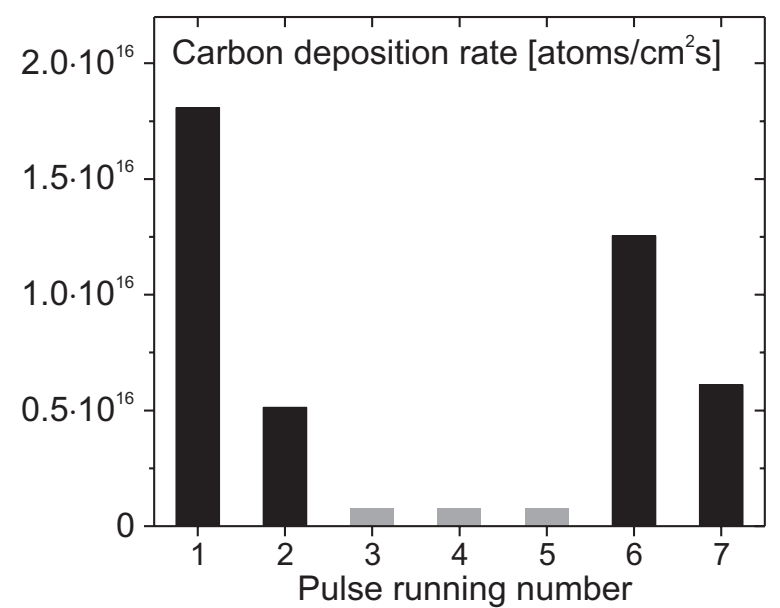

Fig. 6. Carbon deposition rate on the inner louvre QMB of JET during a discharge series (\#\# 68326-68333) to illustrate the shot history effect. Black bars are reproducible discharges with the inner SP at the horizontal target, grey bars at the vertical target. 


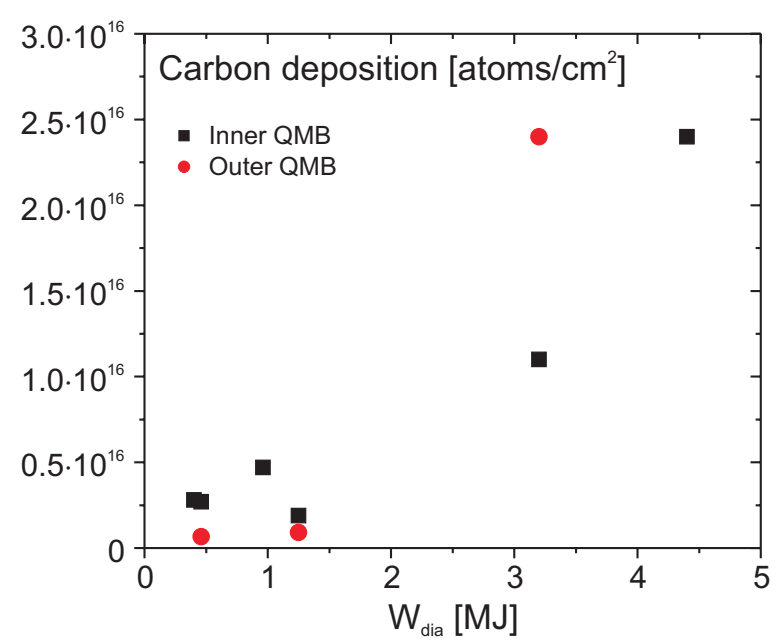

Fig. 7. Carbon deposition in the inner ( $\mathbf{a})$ and outer $(\bullet)$ louvres of JET as function of diamagnetic energy of disruptive discharges. The value of $\mathrm{W}_{\text {dia }}$ is read just before the onset of the thermal quench. 